Correction

\title{
Correction: Pereira, O.; et al. Assessing Pasture Degradation in the Brazilian Cerrado Based on the Analysis of MODIS NDVI Time-Series. Remote Sensing 2018, 10(11) 1761
}

\author{
Osvaldo José Ribeiro Pereira ${ }^{1, *}$, Laerte G. Ferreira ${ }^{2}$, Flávia Pinto ${ }^{1} @$ and Leandro Baumgarten ${ }^{1}$ \\ 1 The Nature Conservancy Brazil, SCN Quadra 05 Bloco A Sala 1407-Torre Sul, Brasília 70715-900, DF, Brazil; \\ flavia.pinto@TNC.ORG (F.P.); lbaumgarten@tnc.org (L.B.) \\ 2 Instituto de Estudos Sócio-Ambientais, Universidade Federal de Goiás, Goiânia 74690-900, GO, Brazil; \\ lapig.ufg@gmail.com \\ * Correspondence: osvaldo.pereira@tnc.org; Tel.: +55-(61)34219133
}

Received: 29 August 2019; Accepted: 15 October 2019; Published: 24 October 2019

After the publication of the research paper [1], the author wishes to make the following correction to this paper. In the "Abstract" section, on page 1, lines 9-10, the sentence "According to our study, around $46 \%$ of the Cerrado pastures are currently degraded, encompassing 37 million hectares" should be "According to our study, around 39\% of the Cerrado pastures are currently degraded, encompassing 18.2 million hectares".

The original version reads as follows:

According to our study, around $46 \%$ of the Cerrado pastures are currently degraded, encompassing 37 million hectares, mostly in areas with a cattle carrying capacity below 1.0 AU ha-1.

The correct sentence should read as follows:

According to our study, around $39 \%$ of the Cerrado pastures are currently degraded, encompassing 18.2 million hectares, mostly in areas with a cattle carrying capacity below 1.0 AU ha-1.

The above changes do not affect the scientific results. The manuscript will be updated and the original will remain online on the article webpage, with a reference to this correction. We apologize for any inconvenience caused by this mistake.

Conflicts of Interest: The authors declare no conflict of interest.

\section{Reference}

1. Pereira, O.J.R.; Ferreira, L.G.; Pinto, F.; Baumgarten, L. Assessing Pasture Degradation in the Brazilian Cerrado Based on the Analysis of MODIS NDVI Time-Series. Remote Sens. 2018, 10, 1761. [CrossRef] 